\title{
A prática médica no Sistema Único de Saúde: quando uma atividade de trabalho pede socorro
}

\author{
Medical practice at the Unified Health System: When \\ a professional activity calls for help
}

Luiz Gonzaga CHIAVEGATO FILHO'

\section{Resumo}

As mudanças ocorridas no universo do trabalho na contemporaneidade atingiram diferentes categorias de trabalhadores, assalariados ou não. Isso alterou de forma marcante a organização e as condições de trabalho, tornando-as mais precárias. O trabalho do médico não escapou a essa lógica. Este artigo é fruto de uma pesquisa qualitativa que objetivou investigar a prática médica no Sistema Único de Saúde de Jaguariúna, São Paulo. Os dados levantados revelam a degradação da atividade de trabalho desses profissionais, motivada pela ausência de um coletivo de trabalho, pelo empobrecimento da identidade profissional e pela vivência de uma atividade contrariada, condições derivadas das mudanças apontadas acima. Entre os principais problemas de saúde associados estão a hipertensão e os transtornos mentais comuns.

Palavras-chave: Médicos; Saúde do trabalhador; Sistema único de saúde.

\begin{abstract}
Changes in the contemporary professional world have affected different category of workers, including salaried employees and self-employed persons. This fact has led to major transformations in work organization and working conditions, making them even more precarious. Medical profession is not an exception and has been equally affected. The present study is based on a qualitative study that investigated the medical practice at the Unified Health System in Jaguariúna, a city in São Paulo state, Brazil. The data gathered show a marked decline of this professional activity due to the lack of work collective, professional identity weakness, and frustrated activity. These conditions result from the changes mentioned above. Among the major health problems associated with the aforementioned conditions are hypertension and common mental disorders.
\end{abstract}

Keywords: Physicians; Occupational health; Unified health system.

\footnotetext{
1 Universidade Federal de São João Del-Rei, Departamento de Psicologia. Praça Dom Helvécio, 74, Dom Bosco, 36301-160, São João Del-Rei, MG, Brasil. E-mail: <lgcfilho@ufsj.edu.br>.

Artigo elaborado a partir da tese de L.G. CHIAVEGATO FILHO, intitulada "Trabalho e saúde: estudo com médicos do Sistema Único de Saúde de Jaguariúna (SP) na perspectiva da Clínica da Atividade”. Universidade de São Paulo, 2011.

Agradecimentos: à Prof. ${ }^{a}$ Dr. ${ }^{a}$ Vera Lúcia Navarro.
} 
Não há dúvidas de que as mudanças tecnológicas e organizacionais ocorridas nas últimas décadas no mundo do trabalho afetaram de alguma forma os diversos setores de atividade produtiva. Essa condição, marcada especialmente pela flexibilidade e intensificação dos ritmos de produção, modificou os motivos de adoecimento e morte da classe trabalhadora e insertou novos desafios, exigências e constrangimentos ao trabalhador, muitas vezes insuperáveis, que impactaram em sua performance e saúde. Com a prática médica não foi diferente. No entanto, ainda é preciso compreender melhor os reflexos dessa modernização paradoxal nas condições de vida e saúde dos trabalhadores, visando estruturar políticas públicas e estratégias de enfrentamento.

Para Campos (2010), a prática médica, mesmo sendo caracterizada pela geração de produtos não materiais e por ser uma atividade ao mesmo tempo dinâmica, manual, reflexiva e, portanto, menos suscetível à racionalização técnica e organizacional, também foi afetada por esse cenário laboral. Alguns estudos, como os de Barbosa, Andrade, Carneiro e Gouveia (2007), Brooks, Gerada e Chalder (2011), Miller (2009), Schraiber (2008), Shen et al. (2012), Wesley e Gerada (2013), demonstraram que essas mudanças, ainda em curso, repercutiram na autonomia profissional, na remuneração (assalariamento crescente), nos múltiplos vínculos empregatícios, na rotinização e precarização do trabalho, na relação médico-paciente, no comportamento ético e, finalmente, na saúde desses profissionais, sobretudo, na saúde mental, acarretando o uso abusivo de drogas e o suicídio.

Diante disso, percebeu-se a necessidade de desenvolver um estudo que procurasse descrever o processo de trabalho médico e seus efeitos na saúde do profissional, bem como identificar aspectos os quais poderiam contrariar ou até mesmo impedir o desenvolvimento individual e coletivo dos trabalhadores no sentido de ampliar a capacidade de ação sobre suas próprias atividades e, consequentemente, superar situações de trabalho desgastantes e degradantes. Esse foi, portanto, o objetivo desta pesquisa qualitativa, feita por meio de um estudo de caso (Yin, 2005) com médicos de Unidades Bá- sicas de Saúde (UBS) do Sistema Único de Saúde (SUS) do município de Jaguariúna, São Paulo.

O referencial teórico adotado fundamentou-se nos estudos da Clínica da Atividade (Clot, 2006, 2007, 2010, 2011, 2013), os quais indicam ser possível compreender o sentido das ações do sujeito em situações de trabalho e as implicações de sua subjetividade em sua atividade real. Buscou-se identificar como o sujeito articula seus recursos pessoais, técnicos, sociais e psíquicos frente à imprevisibilidade das situações de trabalho e como elabora suas estratégias de preservação da saúde. Influenciada pela Ergonomia da Atividade e pela Psicopatologia do Trabalho, a Clínica da Atividade entende o trabalho como uma categoria central para o desenvolvimento do ser humano, podendo, ao mesmo tempo, ser fonte de sofrimento, prazer e criatividade (Lhuilier, 2013; Lima, 2007).

\section{Método}

Nesta pesquisa foram entrevistados 15 médicos das UBS de Jaguariúna, sendo 10 homens e 5 mulheres, de diferentes especialidades: oito clínicos gerais, um geriatra, três pediatras e três ginecologistas. Além destes, participaram o Secretário Municipal de Saúde e a Diretora Administrativa, médico e técnica de enfermagem, respectivamente. $\mathrm{Na}$ época da pesquisa, os médicos das UBS cumpriam uma jornada de, no mínimo, 20 horas semanais controladas pelo cartão de ponto. Alguns deles distribuíam a sua carga horária por mais de uma UBS. Havia 33 médicos efetivamente contratados no período da pesquisa, trabalhando não só nas UBS, mas em outros setores da Secretaria de Saúde.

Os critérios para a inclusão dos entrevistados foram definidos visando garantir a presença de pelo menos um médico de cada UBS e cada especialidade médica oferecida por esses serviços. Os seguintes critérios também foram observados: ser do quadro efetivo e estável da Prefeitura Municipal de Jaguariúna; ter mais de um ano de atuação no emprego; estar no desempenho de atividades profissionais no período da coleta de dados; e aceitar que as entrevistas fossem gravadas e, posteriormente, transcritas na íntegra. 
O número de profissionais entrevistados foi estabelecido pelo critério de saturação, conforme apresentado por Fontanella, Ricas e Turato (2008). Isso acontece quando os dados obtidos passam a apresentar, na avaliação do pesquisador, certa redundância ou repetição, considerando-se ainda os "limites empíricos dos dados, a integração de tais dados com a teoria e a sensibilidade teórica de quem analisa os dados" (Fontanella et al., 2008, p.18).

O estudo contou com duas etapas de entrevistas, todas realizadas nas dependências da UBS do município. A duração das mesmas variou de 30 a 60 minutos, dependendo da disponibilidade dos médicos, pois todos possuíam múltiplos vínculos empregatícios. O fato do pesquisador, à época, trabalhar como psicólogo na Secretaria Municipal de Jaguariúna facilitou o contato inicial e a receptividade dos sujeitos para colaborar com a pesquisa.

Na primeira etapa, foram feitas entrevistas individuais e abertas com os 15 médicos e os dois gestores. Estas eram guiadas por um roteiro semiestruturado que abordava a percepção sobre a profissão médica nos dias de hoje, as condições e a organização do trabalho e os respectivos efeitos na saúde física e mental do profissional, o médico enquanto trabalhador assalariado e as relações com pacientes, colegas, hierarquia e com sua própria atividade no interior das UBS.

Na segunda etapa, cinco médicos que já haviam participado da primeira etapa do estudo, sendo um de cada UBS, foram novamente entrevistados. Entretanto, dessa vez o processo aconteceu de forma diferente. Inicialmente, estava prevista a formação de um grupo para autoconfrontação e uso da técnica de instrução ao sósia, propostas pela Clínica da Atividade (Batista \& Rabelo, 2013; Fernández \& Clot, 2010). No entanto, diante da dificuldade em encontrar horários para reunir os médicos fora do ambiente de trabalho e da ausência de apoio da Secretaria de Saúde do município para a realização dos encontros durante a jornada de trabalho, optou-se por uma adaptação através da realização de entrevistas individuais baseadas nessas técnicas. Entende-se que a autoconfrontação é possível mesmo quando realizada sobre a transcrição de um depoimento, pois, de acordo com Lima (2001, p.140), "trata-se de uma verbalização produzida pelo trabalhador quando se confronta com os dados coletados sobre seu comportamento e quando responde a perguntas que incidem diretamente sobre estes dados".

Dessa forma, a segunda etapa foi realizada com o pesquisador apresentando a transcrição do material coletado nas entrevistas da primeira, a fim de confirmar opiniões, esclarecer dúvidas ou aprofundar determinado tema, além de algumas interpretações iniciais do pesquisador sobre os dados obtidos. Nesse momento, foi possível confirmar, de forma conjunta, um aspecto presente na situação de trabalho que era comum a todos os entrevistados. Tratava-se da dificuldade relacionada à organização das consultas, mais precisamente a dificuldade de adaptar-se à regra elaborada pelos gestores de que cada consulta deveria durar apenas quinze minutos.

Na sequência, fez-se a cada médico a pergunta regra da técnica do sósia: suponha que eu seja o seu sósia e que amanhã irei substituí-lo, quais seriam as instruções, relativas à consulta médica e à dificuldade identificada acima, que eu deveria seguir para que ninguém percebesse a substituição? A ideia é que cada sujeito entrevistado pudesse orientar e instruir o pesquisador em como proceder em uma situação real de trabalho, indicando o que é feito habitualmente, o que deve ser evitado e os procedimentos adequados, de forma a revelar, como indicam Batista e Rabelo (2013, p.5), "os subentendidos e os implícitos que sua atividade comporta. O resultado dessa fase é, sobretudo, a descrição das escolhas feitas pelo sujeito na realização de sua atividade".

$\mathrm{Na}$ apresentação dos dados, optou-se por substituir o nome dos participantes por letras do alfabeto, visando garantir o sigilo dos depoimentos. A análise foi construída por meio de um processo contínuo em busca da identificação de dimensões, categorias, tendências, padrões e relações, desvendando-Ihes o significado. Trata-se de um processo complexo, não linear, que implica um trabalho contínuo de redução, organização e interpretação dos dados obtidos. 
A presente pesquisa foi aprovada pelo Comitê de Ética em Pesquisa (CEP) da Faculdade de Filosofia, Ciências e Letras de Ribeirão Preto (Processo CEP-FFCLRP n 387/2008). Tanto na primeira quanto na segunda etapa os médicos foram esclarecidos sobre os procedimentos da pesquisa e, em seguida, assinaram o Termo de Consentimento Livre e Esclarecido.

\section{Resultados e Discussão}

\section{A prática médica no Sistema Único de Saúde de Jaguariúna}

De acordo com os dados levantados, é possível afirmar que a prática médica nas UBS de Jaguariúna passava, à época do estudo, por um momento de fragilização do ofício, ou seja, fragilização das trocas intersubjetivas estabelecidas pelo coletivo de trabalho. Isso representa um desgaste nos recursos técnico e psicológicos para execução das atividades previstas (Clot, 2010, 2013).

Essa degradação, como será possível observar, aparece quando se analisa a dinâmica interna do ofício em suas quatro dimensões, conforme proposto por Clot (2010). Tem-se, portanto, as dimensões impessoal, interpessoal, transpessoal e pessoal, sendo que cada uma delas é o meio do desenvolvimento da outra e, dessa forma, não devem ser vistas isoladamente.

Na perspectiva da Clínica da Atividade, ofício não é apenas um conjunto de ações, práticas e atividades partilhadas por uma dada categoria profissional em ambiente de trabalho. Nesse caso, ele assume uma função psicológica importante na medida em que é definido como um instrumento de ligação fundamental para o desenvolvimento de um conjunto de instâncias ou dimensões estabelecidas nas relações entre os sujeitos e a organização de trabalho, que será detalhado mais adiante (Clot, 2010, 2013).

A dimensão impessoal está presente na prescrição das tarefas e é o primeiro e fundamental recurso que um indivíduo deve possuir quando ponto de partida de uma ação. A ausência da prescrição oficial, ou sua ineficiência, podem comprometer a execução das atividades (Clot, 2010).

Em relação a essa dimensão, na época da pesquisa todos os médicos estavam submetidos a contratos regidos pela Consolidação das Leis do Trabalho, cumprindo uma jornada de, no mínimo, 20 horas semanais e atendendo quatro pacientes por hora, agendados de quinze em quinze minutos. Essa regra formal foi a mais comentada e questionada nos depoimentos e já evidencia a presença da ideologia gerencialista no sentido de que exige o cumprimento de uma meta e a racionalização da produção. Os clínicos gerais foram os que mais se queixaram a esse respeito, como pode ser observado nos relatos a seguir:

Eu gosto de trabalhar com tranquilidade, o meu tempo, o tempo que eu preciso para o meu paciente, não o tempo que o serviço quer me dar. Atender um paciente [na clínica médica] a cada 15 minutos para mim é uma tortura (Médico F).

Um dos problemas daqui é a questão do tempo [a regra dos 15 minutos]. Principalmente se você faz clínica médica, pois aborda-se muitas coisas para chegar ao diagnóstico e acaba sendo muito estressante ter que fazer rápido. É preciso correr e você não consegue ser tão atencioso quanto gostaria. Se fosse uma consulta de $10 \mathrm{mi}$ nutos a mais, tipo meia hora ao invés de 15 minutos, o estresse seria muito menor (Médica C).

Embora a autonomia profissional dos médicos, de acordo Schraiber (2008), tenha, historicamente, se configurado como um elemento fundamental para o exercício da profissão, garantindo liberdade para se colocar no processo de trabalho, nota-se uma progressiva perda dessa autonomia nos serviços de saúde pública. Estes são cada vez mais administrados com base em práticas e referências de mercado, ou seja, na ideologia gerencialista (Campos, 2010; Melo, Assunção, \& Ferreira, 2007).

As propostas dessa ideologia caracterizam-se pela busca em descrever, explicar, interpretar e analisar o mundo e a realidade circundante a partir 
de conceitos e categorias tidos como naturais e oriundos da gestão privada, o que oculta a realidade do poder subjacente. Nas últimas décadas, essa configuração ideológica presente nas relações de trabalho tem influenciado a sociedade e vem ganhando espaço no setor público brasileiro, considerado demasiadamente arcaico e burocrático (Chanlat, 2002; Gaulejac, 2007; Wood Junior \& Paula, 2010).

No depoimento dos gestores, foi possível identificar claramente os elementos da ideologia gerencialista, como as cobranças por mais flexibilidade, trabalho em equipe, comprometimento e vontade para o trabalho etc. A fala a seguir, de um dos gestores, foi emblemática:

O dia que isso aqui for gerenciado como uma empresa, para fazer bem feito, entendeu... . O dia que a gente aprender a fazer isso, todo mundo, você tem que participar! Você tem que fazer mudar! Tem que ser profissional! Acima de qualquer coisa, acima de vontade política, amiga etc.! (Gestor A).

Ao final das entrevistas com os gestores, fica claro que os problemas no desenvolvimento de políticas públicas de saúde estão mais relacionados às estratégias de gestão do que ao debate epistemológico sobre o assunto. Isso se refletia no modelo de atenção primária adotado pelo município na época da pesquisa: o convencional ou hegemônico. Esse modelo, de acordo com Paim (2008), é centrado no atendimento de doentes e orientado pela demanda espontânea da população ou induzida pela oferta. Trata-se da promoção de uma assistência médica curativa e centrada na figura do profissional médico, como atestam os depoimentos a seguir:

Aqui a gente trabalha muito na cura, a gente não faz uma prevenção antes (Gestor A).

Entendo que as UBS teriam que trabalhar na prevenção e na promoção da saúde. Mas isso eu nunca fiz. Só atendo a demanda, atendo a pessoa que já vem com um problema (Médico B).

Além da ausência de uma discussão acerca da política assistencial de saúde a ser adotada no município, notou-se a ausência de uma "prescrição técnica" de como proceder antes, durante e depois das consultas. Confirmando os achados de Clot (2010), essa condição comprometia a execução das atividades e gerava insegurança quanto ao que e como as coisas deveriam ser feitas, notadamente nos médicos com menos tempo de atividade no município.

Até agora não foi feita se quer uma reunião comigo, nada! Fui lá e pronto! [um ano e meio de trabalho na UBS] (Médico B).

Eu fui jogado lá no posto de saúde, não recebi nenhum treinamento! Nem pra preencher os formulários. Eu era recém-formado, primeiro emprego. Fui lá e tive que atender 32 pacientes por dia, com o que tinha lá. Isso desgasta [um ano de trabalho na UBS] (Médico I).

A ausência ou a insuficiência das prescrições e, como se verá adiante, a impossibilidade da renovação individual ou coletiva da dimensão impessoal por parte dos profissionais médicos foram os primeiros sinais de que a dinâmica da função psicológica do ofício poderia estar enfraquecida, proporcionando desgastes e riscos à saúde dos médicos das UBS. No entanto, as dificuldades encontradas na dimensão impessoal poderiam ser superadas pelos profissionais através do acesso aos recursos interpessoais construídos através de trocas e diálogos entre os pares sobre as situações de trabalho vivenciadas nas UBS. Trata-se da dimensão interpessoal, momento em que ofício se mostra entre os profissionais e em cada um deles à medida que dialogam sobre o real do trabalho, como um apoio social (Clot, 2010).

Porém, os recursos interpessoais também não estavam suficientemente disponíveis na atividade de trabalho dos médicos das UBS. A maioria dos entrevistados reconheceu não só a ausência dos mesmos, como também sua importância para melhorar o desempenho da própria ação:

Ter uma melhor integração com os colegas [sobre o que está faltando para melhorar o trabalho]. Os médicos precisam ser mais ligados, mais próximos, acho que é muito individualista (Médica J). 
Aqui [Jaguariúna] cada um faz a sua parte. Cada um no seu quadrado, mas eu acho que esses quadrados deviam ser integrados, porque um profissional precisa do outro (Médico I).

Um negócio que eu percebi também é que a medicina é uma profissão solitária. Você tem que, às vezes, tomar a decisão sozinho. Como aqui [Jaguariúna], que você está em contato com muita gente, mas está solitário... . É uma profissão muito isolada (Médico $M)$.

Está-se diante, portanto, da segunda evidência da fragilização da função psicológica do ofício. Essa troca coletiva para realizar a tarefa e repensá-la, quando bem-sucedida, produz a dimensão transpessoal do ofício, que representa a história e a memória profissional de uma atividade de trabalho, a qual não pertence a ninguém e deve estar à disposição de todos os pares. Trata-se do gênero profissional (Clot, 2010).

Não se pode, então, tratar da atividade de trabalho sem colocar a questão do lugar que os outros (parceiros da atividade ou gestores) ocupam nesse contexto. Como lembra Lhuilier (2013, p.484), "a atividade é sempre o encontro singular de um sujeito e de uma situação concreta, encontro onde o outro é sempre convocado". Nesse sentido, toda atividade é endereçada, possuindo um ou vários interlocutores e também é destinatária da atividade dos outros. Mesmo o trabalhador estando só pode-se falar da presença de um coletivo invisível invadindo e compondo o real de sua atividade.

O gênero profissional deve ser considerado como um "prescrito coletivo", ou seja, um conjunto de regras não escritas, de caráter histórico e transitório, que um coletivo de trabalhadores partilha em um determinado momento. Trata-se de um recurso coletivo o qual intercede na atividade pessoal e opera de maneira tácita, contribuindo para que os constrangimentos e imprevistos surgidos e vividos nos ambientes de trabalho sejam categorizados e administrados para a obtenção de bons resultados e para a preservação da saúde, fundamental no desenvolvimento da capacidade de ação individual e coletiva sobre as situações de trabalho (Clot, 2006, 68
Porém, de acordo com Clot (2010), sem contato com esse recurso genérico ou sem o respaldo do coletivo de trabalho, a atividade individual fica abandonada e insegura. Nota-se a ausência de disponibilidade técnica e psicológica do coletivo de trabalho, que não constrói uma linguagem comum ou uma estratégia coletiva em relação às condutas adotadas pelos trabalhadores em certas situações. Como não há coletivo de trabalho e sim uma reunião de indivíduos, cada profissional utiliza uma tática diferente para enfrentar o real. Isso foi percebido na maioria dos relatos sobre os procedimentos de uma consulta médica:

Por dia você vai atender 16 pacientes! Ok, você tem um esquema já definido de trabalho... isso acho que já é de personalidade, cada um faz de um jeito (Médica M).

E é engraçado porque eu tento chegar bem próximo mesmo deles [pacientes]. Explicar de uma maneira simples, com palavras que os leigos usam. Mas eu sinto que eu faço parte da minoria, principalmente aqui [UBS] (Médica L).

Essa é uma questão muito pessoal, tem gente que usa "corticoide" ou "Melhoral", por qualquer coisa. Eu não discuto isso, é uma questão pessoal e não acho que estou nem certo nem errado (Médico O).

Tem-se, então, a terceira evidência da fragilização da função psicológica do ofício. A maioria dos médicos concorda que a forma como procedem nas consultas está mais ligada a uma questão pessoal ou de personalidade, o que indica a ausência do recurso transpessoal comentado acima.

A construção de um espaço para análise e transformação das atividades de trabalho, tentativa realizada na segunda etapa desta pesquisa com o uso de entrevistas baseadas no método de Instrução ao Sósia, apesar de facilitar a compreensão dos procedimentos de uma consulta médica nas UBS, não foi suficiente para restaurar as qualidades do gênero profissional e revitalizar o ofício enfraquecido. Assim como Clot (2010), entende-se que o reconhecimento da dinâmica e da função psicológica do ofício pela hierarquia é imprescindível para sua 
construção ou reabilitação. Entretanto, os médicos que participaram dessa etapa reconheceram a importância da confrontação como estratégia para o desenvolvimento de suas atividades:

É uma coisa interessante de você ver [a descrição da própria atividade para o suposto sósia substituto]. Eu gostaria de ver... assistir você sendo representado, como você é fielmente... não seria bom? Do que a gente teria medo? De ver defeito, não é? (Médica M).

Foi bom fazer isso, eu tentei imaginar assim, será que eu estou falhando em alguma coisa? É uma coisa meio... acho que lá dentro da sua cabeça tem uma coisinha assim pensando, não tem? Tem! (Médica L). Imaginar alguém te representando? Foi como você se ver de fora de você mesma. Se eu pudesse sair mais e me ver de fora. Seria ótimo para a gente melhorar. Será que eu estou fazendo alguma coisa que eu estou dando mancada? É interessante porque pode ter coisa que eu vou gostar e pode ter coisa que eu não vou gostar (Médica M).

No entanto, em tempos de avanço e consolidação da ideologia gerencialista, os gestores das UBS do município centralizavam as decisões sobre a organização do trabalho, não permitindo que os profissionais médicos, nas palavras de Clot (2010), tivessem o "prazer de cuidar" de sua atividade. Nesse caso, foi possível evidenciar os constrangimentos relatados pelos médicos em sua capacidade de ação sobre o próprio fazer que, por sua vez, restringiam as margens de manobra e as possibilidades de regulação da atividade, como os relatos abaixo parecem indicar:

Não tem jeito, é isso mesmo. É passado pra gente que deve funcionar no sistema de convênio, tudo normatizado e que é isso mesmo. $O$ entendimento é esse (Médica L).

Hoje em dia a gente tenta desenvolver as coisas, mas... na verdade, acaba tendo que se adaptar mesmo (Médica B).

Isso aí é a parte que eu não me importo [regra dos 15 minutos]. Acho que faz parte da realidade, você acostuma com isso realmente... mas nunca é do jeito que a gente quer mesmo (Médica C).
Na proposta de Clot (2010), a dimensão pessoal do ofício só é alcançada com o domínio das dimensões impessoal e transpessoal por intermédio das trocas intersubjetivas do coletivo de trabalho, ou seja, não é algo possível de se realizar sozinho. Nesse instante, o trabalhador está pronto para assumir as responsabilidades do desenvolvimento da função psicológica do ofício diante dos imprevistos de uma dada situação de trabalho. Para tanto, é preciso legitimar e dar tempo para que essa dinâmica, cujo desenvolvimento é imprevisível, se consolide e renove sua vitalidade social.

No caso do enfraquecimento desse percurso intersubjetivo, como é o caso entre os médicos da UBS, diante das dificuldades encontradas para o desenvolvimento de suas atividades, resta ao profissional optar por uma transgressão individual, ou seja, tomar uma decisão sem o apoio e respaldo dos colegas. Esse fato, observado em alguns relatos, pode acarretar problemas com hierarquia, pacientes, os próprios colegas ou até consigo mesmo, em um processo de "autoculpabilização" pelos problemas da suposta ineficiência da atividade de trabalho, sem estabelecer qualquer relação com suas condições e organização.

A gente deveria ter mais tempo para atender cada paciente. Mas eu sou mais lenta mesmo (Médica L).

Acho que... culpa nossa, dos médicos mesmo [de ter que se submeter às regras administrativas], que começaram, talvez por ganância, a se vender, vamos falar nesses termos, a se vender muito barato (MédiCO I).

A ausência dos recursos coletivos para ação também pode ser evidenciada nos relatos sobre as estratégias ou tentativas de enfrentamento dos imprevistos de uma dada situação de trabalho, na medida em que se mostraram pessoais e particulares. Sem acesso ao coletivo de trabalho para enfrentar o real, há duas possibilidades mais recorrentes, ambas ineficientes: esconder-se atrás da tarefa prescrita, da prescrição oficial, ou transgredir individualmente aquilo que era para ser feito. Nesses casos, o dado genérico necrosado se opõe à criação coletiva e individual, suspendendo ou colocando 
obstáculos ao desenvolvimento da atividade. Para evitar essa degeneração do gênero profissional, a confrontação e a controvérsia são indispensáveis, buscando estimular intercâmbios coletivos e conservar na atividade individual e na tarefa prescrita um devir.

No entanto, sabe-se que atualmente, em tempos de predomínio da ideologia gerencialista, a função do trabalho de dar sustentação ao desenvolvimento social dos sujeitos (função psicológica), por ser fonte de iniciativa e criatividade, é pouco explorada (Clot, 2007, 2010; Gaulejac, 2007).

Cada cruz no meu estetoscópio é uma cruz que pesa [falando sobre a morte de pacientes]... talvez eu precisasse de um psicólogo, mas a minha esposa é muito companheira, a gente vai conversando (Médico B).

Acho que é levar na boa mesmo. Procurar não se carregar demais e resolver o que você pode. Isso você aprende com o tempo mesmo. Ter um paciente que teve uma doença muito ruim dá uma angústia na gente. Pra mim demora dias pra digerir (Médico N).

Eu tenho que chorar um pouco e passa, vou fazer alguma coisa que eu gosto, como ver vitrine, por exemplo, passear num lugar em que você possa não ser médico (Médico M).

De forma surpreendente, ainda sobre as estratégias de enfrentamento, alguns médicos recorrem ao apoio religioso. Um dos entrevistados afirma, inclusive, que a ausência da religião é um dos motivos que levam os demais colegas a adoecerem.

Depende muito de, vamos dizer, pessoalmente como é que eu estou começando o meu dia, sabe? Se eu me proponho a estar melhor e se eu falo: Deus, eu estou indo trabalhar, eu não estou com paciência hoje, mas eu espero que o Senhor me dê essa paciência... . Acaba sendo uma estratégia que funciona (Médica A).

Ficam doentes [os colegas], porque não conhecem a Deus, não é? Claro que é! Você conhece alguma pessoa que tenha problema de saúde e que está espiritualmente bem?... . Eu creio assim: se estiver dentro dos planos de Deus para minha vida, não
"Ah, mas está tudo ótimo na minha vida, mas meu trabalho não tá legal". Isso acontece porque não é o trabalho que Deus escolheu para ele. É falta de ouvir Deus! (Médica H).

Eu rezo todo dia antes do trabalho. Eu acordo, eu já falo: olha Deus, faz hoje o meu dia ser bom. Se eu fizer alguma coisa errada você me mostra na hora! Por favor, você mostra ou você dá uma chance de eu concertar (Médica M).

Para Clot (2006, 2010), quando o trabalho não exerce mais sua função psicológica, quando ele se confunde com execução de procedimentos, constatam-se vivências de impotência, ressentimento e melancolia ou o contrário, euforia profissional. Com o avanço da ideologia gerencialista, exige-se do trabalhador uma disponibilidade psicológica que é, ao mesmo tempo, sufocada pela gestão na imposição dos "jeitos de ser". Paradoxalmente, pela prescrição ou reordenamento da subjetividade, a gestão não fornece a sustentação necessária para o desenvolvimento dos coletivos de trabalho, o que finda por contrariar, suspender ou impedir o desenvolvimento da própria atividade executada nos respectivos locais de trabalho. Trata-se da amputação do poder de agir dos trabalhadores sobre as situações de trabalho, o que, conforme apontaram os depoimentos acima, parece afetar o cotidiano dos médicos das UBS de Jaguariúna.

Esses casos onde se constata a ausência de um coletivo e a vivência de uma atividade contrariada, são desgastantes e geram sofrimentos tanto físico quanto mental. Assim, os trabalhadores precisam desenvolver uma ampla gama de mecanismos de regulação, os quais geralmente asseguram os resultados, mas eventualmente fazem fracassar. As dificuldades, a impossibilidade de criar e gerir as regras da própria atividade ou, como afirma Canguilhem (1978), a impossibilidade de criar e instaurar normas vitais, de produzir, transformar e interagir com o meio e com os outros provavelmente explicam os principais problemas de saúde relatados pelos médicos, como a hipertensão e os transtornos mentais menores.

Sempre tem [impacto na saúde]. Outro dia a pressão subiu. Descompensou (Médico B). 
Agora só a pressão que começou a subir novamente. Eu acho que, depois que eu comecei a fazer esse posto [UBS], começou a mexer na minha pressão de novo (Médica C).

Lógico que faz mal trabalhar num serviço que te exige atenção total e mental. No meu caso, sou hipertenso. Por exemplo, eu tomo três diferentes tipos de anti-hipertensivo e tomo ansiolítico também (Médico I).

Os transtornos mentais comuns podem ser indicadores de que o trabalho não exerce mais a sua função psicológica. Alguns estudos evidenciaram a relação entre a atividade profissional em saúde, incluindo os médicos, e a incidência de transtornos mentais menores (Braga, Carvalho, \& Binder, 2010; Cabana, Ludermir, Silva, Ferreira, \& Pinto, 2007; England, 2008). Alguns relatos dos médicos das UBS confirmam essa relação:

A gente tem um desgaste emocional, que eu acho alto, porque você se envolve emocionalmente com o paciente o dia inteiro e esse é um aspecto que eu acho difícil administrar (Médico O).

O estresse é um problema. Falar que você não chega estressada, cansada, desanimada, é mentira. Ao ponto de eu falar: preciso de férias, senão eu vou chutar a parede (Médico E).

Estresse [quando perguntado se teve problemas de saúde]. Eu já tive um episódio de depressão há sete anos, por aí. Mas era uma depressão com um componente de ansiedade tão grande que se eu parasse era pior, então eu vinha trabalhar. Eu precisava trabalhar (Médica A).

Nas entrevistas, também foi comum os médicos se recordarem de episódios envolvendo problemas de saúde ocorridos com os colegas. Casos de alcoolismo e depressão foram os mais relatados:

Eu já vi desde reação aguda ao estresse, em que o individuo tem que tomar os antidepressivos, até conflito com paciente, com equipe. Já vi muitos colegas com problema de alcoolismo e até extremos de suicídio, em número bem pequeno. Mas, basicamente, depressão e alcoolismo (Médico D).
Poucos médicos que trabalham comigo não tomam remédio para alguma coisa do tipo diabetes, hipertensão e ansiedade. Não estou me lembrando de ninguém agora. Talvez algum jovenzinho que acabou de chegar. Mas se já trabalham a quinze anos, dez, quinze anos, ninguém escapa. Quem vive nessa rotina toma remédio para ansiedade, depressão e pressão alta. Quase todo mundo (Médico I).

Entretanto, os dados revelam o descaso e o pouco cuidado dos médicos com a própria saúde. Estes acabam não reconhecendo ou ignorando a qualidade dos sintomas que apresentam, fruto talvez da incerteza sobre com quem se pode contar no ambiente de trabalho.

Eu percebo assim: bom, agora eu não posso desacelerar, agora eu não posso segurar minha agenda, agora eu não posso diminuir o atendimento, eu tenho uma demanda programada para isso daí... . Dá pra perceber quando o trabalho afeta? Dá, mas você meio que descarta isso logo. Por que não tem jeito, é esse o esquema. Então tudo bem (Médica L).

Eu, particularmente, sou uma pessoa que não pensa muito na própria saúde. Pouco faço exame. É só quando já estou muito ruim mesmo. Acho que nem é arrogância, mas é achar que está tudo bem, que você conhece, e de repente quando vai ver não é bem assim. A gente tem que aprender a ser paciente também (Médica M).

Graças a Deus, eu tenho uma saúde boa. Estou atualmente, aí com uma gripe de um mês, que agora contaminou e virou uma sinusite. Ontem eu estava péssimo, o antibiótico começou a fazer efeito, mas nada especial. Eu tenho uma boa saúde e me sinto bem trabalhando (Médico F).

\section{Conclusão}

Os dados obtidos na pesquisa revelaram que os médicos das UBS estão submetidos a um processo de trabalho que Ihes tira a autonomia para gerir as próprias ações, Ihes sobrecarregam e expõem a 
situações de muita pressão, cujos efeitos mais relatados foram a hipertensão e os transtornos mentais menores. Essa condição se agrava na medida em que se constata a ausência de um coletivo de trabalho, o que enfraquece a dinâmica do ofício e favorece a vivência de uma atividade contrariada, impedindo que o trabalho exerça plenamente a sua função psicológica.

Como afirma Lhuilier (2012, p.23), "a atividade impedida, 'contrariada', 'paralisada', 'suspensa' deve ser admitida, quando se quer que as relações entre saúde e trabalho sejam esclarecidas". Compreende-se dessa forma o desenrolar de inúmeras patologias no trabalho na medida em que, continuando com Lhuilier (2012, p.23),

a calibragem e a intensificação do gesto que acompanham a organização taylorista do trabalho tendem a reduzir a energia despendida e otimizar a produtividade. Fazendo isso, elas contribuem para um aumento da carga física e psíquica de trabalho, forçando o operador à inibição de toda iniciativa e movimento espontâneo. A imposição dessa formatação condena o operador não somente à realização de gestos repetitivos, mas também a uma contenção que é uma tensão contínua (Lhuilier, 2012, p.23).

Nesse contexto, os estudos desenvolvidos em situações de trabalho reais, fundamentados pelas premissas da Clínica da Atividade, indicam que ao invés de cuidar das pessoas é preciso cuidar do trabalho para se obter avanços na saúde dos trabalhadores. Para Clot (2010, p.222), cuidar do trabalho é transformar a sua organização, ou seja, "criar situações e encontrar técnicas nas quais se transformem os trabalhadores em sujeitos da situação, fazendo-os protagonistas da transformação".

As dimensões do ofício da prática médica descritas anteriormente parecem ter um efeito concreto na saúde desses trabalhadores. Isso se deve ao fato de que, por meio delas, eles se reconhecem no ofício e se transformam em sujeitos de uma atividade mediatizante no decorrer da qual é possível recuperar o poder de agir. Portanto, a transfor- mação coletiva do trabalho real dos sujeitos parece ser fundamental para as construções subjetivas, garantindo a transfiguração da organização oficial a fim de mantê-la como instrumento diante do real. Para tanto, é mais importante promover, durante a jornada de trabalho, um tempo de confrontação sobre o mesmo, com o intuito de desenhar os contornos de uma configuração genérica, do que reconhecer o sofrimento em situação de trabalho, com vistas a criar uma forma de gerenciamento do estresse (Clot, 2010, 2013; Lima, 2010).

Diante desse cenário profissional, devem ser estimulados procedimentos hierárquicos nos serviços de saúde, os quais não se restrinjam a questões administrativas e burocráticas, mas que ampliem sua atuação em direção à prescrição técnica do fazer médico, propondo ações de saúde vinculadas aos princípios básicos do SUS e que privilegiem a atividade real de trabalho. Além disso, esses procedimentos devem reconhecer a dinâmica do ofício em questão e as trocas intersubjetivas subjacentes fundamentais para o desenvolvimento do cotidiano dos profissionais médicos. Isso implica respeitar a autonomia técnica da profissão e não reproduzir os seus interesses corporativos.

Apesar de não ter sido possível construir e consolidar, nesta pesquisa, um espaço para análise e transformação das atividades laborais, espera-se que este estudo, mais do que registrar e reconhecer o sofrimento dos médicos, evidencie a importância de se reconhecer a heterogeneidade da ação dos funcionários nos ambientes de trabalho e o seu papel ativo na organização e desenvolvimento das atividades. Nesse caso, concordando com Clot (2010, p.284), ao invés de favorecer o desenvolvimento de "um novo campo de gestão dos recursos humanos", alinhado à ideologia gerencialista, a ideia é contribuir para o desenvolvimento de situações de trabalho mais saudáveis e estimulantes. Finalmente, reconhecer a importância da vitalidade do ofício talvez seja o primeiro passo para o desenvolvimento de políticas públicas que orientem a gestão de serviços de saúde no sentido de combater a precarização e a degradação da atividade de trabalho nesses locais. 


\section{Referências}

Barbosa, G. A., Andrade, E. O., Carneiro, M. B., \& Gouveia, V. V. (Orgs.). (2007). A saúde dos médicos no Brasil. Brasília: Conselho Federal de Medicina.

Batista, M., \& Rabelo, L. (2013). Imagine que eu sou seu sósia: aspectos técnicos de um método em clínica da atividade. Cadernos de Psicologia Social do Trabalho, 16(1), 1-8.

Braga, L. C., Carvalho, L. R., \& Binder, M. C. P. (2010). Condições de trabalho e transtornos mentais comuns em trabalhadores da rede básica de saúde de Botucatu (SP). Ciência \& Saúde Coletiva, 15(1), 1585-1596.

Brooks, S. K., Gerada, C., \& Chalder, T. (2011). Review of literature on the mental health of doctors: Are specialist services needed? Journal of Mental Health, 20(2), 146-156.

Cabana, M. C. F. L., Ludermir, A. B., Silva, E. R., Ferreira, M. L., \& Pinto, M. E. R. (2007). Transtornos mentais comuns em médicos e seu cotidiano de trabalho. Jornal Brasileiro de Psiquiatria, 1(56), 33-40.

Campos, G. W. S. (2010). Cogestão e neoartesanato: elementos conceituais para repensar o trabalho em saúde combinando responsabilidade e autonomia. Ciência \& Saúde Coletiva, 15(5), 2337-2344.

Canguilhem, G. (1978). O normal e o patológico. Rio de Janeiro: Forense-Universitária.

Chanlat, J. F. (2002). O gerencialismo e a ética do bem comum: a questão da motivação para o trabalho nos serviços públicos. In Anais do VII Congreso Internacional del CLAD sobre la Reforma del Estado y de la Administración Pública, Lisboa, Portugal. Recuperado em agosto 6, 2010, de http://unpan1.um.org/intradod groups/public/documents/CLAD/clad0043316.pdf

Clot, Y. (2006). A função psicológica do trabalho. Petrópolis: Vozes.

Clot, Y. (2007). Trabalho e sentido do trabalho. In: Falzon, P. (Org.), Ergonomia (pp.265-280). São Paulo: Blucher.

Clot, Y. (2010). Trabalho e o poder de agir. Belo Horizonte: Fabrefactum.

Clot, Y. (2011). Clínica do trabalho e clínica da atividade. In P. F. Bendassolli \& L. A. Sobboll (Orgs.), Clínicas do trabalho: novas perspectivas para a compreensão do trabalho na atualidade (pp.71-83). São Paulo: Atlas.

Clot, Y. (2013). O ofício como operador de saúde. Cadernos de Psicologia Social do Trabalho, 16(Esp.), 1-11.

England. Department of Health. (2008). Mental health and ill health in doctors. London: Department of Health.

Fernández, G., \& Clot, Y. (2010). Entrevistas en autoconfrontación: Un método en clínica de la actividad. Informática na Educação: Teoria \& Prática, 13(1), 11-16.

Fontanella, B. J. B., Ricas, J., \& Turato, E. R. (2008). Amostragem por saturação em pesquisas qualitativas em saúde: contribuições teóricas. Cadernos de Saúde Pública, 24(1), 17-27.
Gaulejac, V. (2007). Gestão como doença social: ideologia, poder gerencialista e fragmentação social. São Paulo: Ideias e Letras.

Lima, F. P. A. (2001). A formação em ergonomia: reflexões sobre algumas experiências de ensino da metodologia de análise ergonômica do trabalho. In C. Kiefer, I. Faga, \& M. R. Sampaio (Orgs.), Trabalho, saúde e educação: um mosaico em múltiplos tons (pp.133-148). São Paulo: Fundacentro.

Lima, M. E. A. (2007). Trabalho e identidade: uma reflexão à luz do debate sobre a centralidade do trabalho na sociedade contemporânea. Educação \& Tecnologia, $12(3), 5-9$.

Lima, M. E. A. (2010). Réplica 2: réplica ao artigo "Tentativas de suicídio entre bancários no contexto de reestruturação produtiva". Revista de Administração Contemporânea, 14(5), 949-955.

Lhuilier, D. (2012). A invisibilidade do trabalho real e opacidade das relações saúde-trabalho. Trabalho \& Educação, 21(1), 13-38.

Lhuilier, D. (2013). Trabalho. Revista Psicologia \& Sociedade, 25(3), 13-38.

Melo, E. M. C., Assunção, A. A., \& Ferreira, R. A. (2007). $\mathrm{O}$ trabalho dos pediatras em um serviço público de urgências: fatores intervenientes no atendimento. Cadernos de Saúde Pública, 23(12), 3000-3010.

Miller, L. (2009). Doctors, their mental health and capacity for work. Occupational Medicine, 59(1), 53-55.

Paim, J. S. (2008). Modelos de atenção à saúde no Brasil. In L. Giovanela, S. Escorel, L. V. C. Lobato, J. C. Noronha, \& I. A. Carvalho (Orgs.), Politicas e sistema de saúde no Brasil (pp.547-573). Rio de Janeiro: Fiocruz.

Schraiber, L. B. (2008). O médico e suas interações: a crise dos vínculos de confiança. São Paulo: Aderaldo \& Rothschild.

Shen, L. L., Lao, L. M., Jiang, S. F., Yang, H., Ren, L. M., Ying, D. G. C., \& Zhu, S. Z. (2012). A survey of anxiety and depression symptoms among primary-care physicians in China. The International Journal of Psychiatry in Medicine, 44(3), 257-270.

Wesley, A., \& Gerada, C. (2013). When doctors need treatment: An anthropological approach to why doctors make bad patients. Retrieved December 13, 2015 from http://careers.bmj.com/careers/advice/viewarticle.html?id=20015402

Wood Junior, T., \& Paula, A. P. P. (2010). O culto da performance e o indivíduo S.A. In A. Ehrenber (Org.), O culto da performance (pp.197-208). São Paulo: Ideias e Letras.

Yin, R. K. (2005). Estudo de caso: planejamento e métodos ( $3^{\mathrm{a}} \mathrm{ed}$.). Porto Alegre: Bookman.

Recebido: fevereiro 2, 2016

Versão final: maio 6, 2016

Aprovado: maio 24, 2016 
